\title{
Gender inequality among champions and players' reception of gender disproportion of utility support champions in League of Legends
}

Doo Heon Song, Hae Kyung Rhee, Jeong Hoon Kim

Department of Computer Games, Yong-In SongDam College, Yong-in, Republic of Korea

\begin{tabular}{l}
\hline \hline Article Info \\
\hline Article history: \\
Received Jul 31, 2020 \\
Revised Sep 22, 2020 \\
Accepted Oct 9, 2020
\end{tabular}

Keywords:

Content analysis

Female character portrayal

Gender discrimination

League of Legends

Social role theory

\begin{abstract}
Designing female character in video game has been criticized as being sexually objectified and underrepresented in quantity (number of characters and their appearance rate in the game) and in quality (take only secondary role and inferior ability statistics given). In this paper, we analyze world leading multiple-user online battle arena game League of Legends to see if previously criticized gender inequality of champions still stands and conduct a survey of 1,403 players of that game and ask how they feel about serious gender disproportion of utility support champions (all females). The result shows that League of Legends still has serious gender disparity in performance parameters and there has been only a small change in 5-year span (2014-2019). The survey result tells us that game players also feel political incorrectness of such gender disproportion, but they accept such gender prototype because they have been taught as such as social role theory explains gender inequality issues.
\end{abstract}

This is an open access article under the CC BY-SA license.



\section{Corresponding Author:}

Doo Heon Song

Department of Computer Games

Yong-In SongDam College

571-1 Cheo-in Gu, Yong-in 17145, Republic of Korea

Email: dsong@ysc.ac.kr

\section{INTRODUCTION}

Mass media has the potential to influence many behavioral social norms including self-esteem, gender identity and even sexual behaviors [1]. As a form of media, analyzing video game messages can be useful in identifying the gender roles and stereotypes presented therein [2]. Unfortunately, recent game contents analysis reports [3-5] reveal that female characters in video game are vastly underrepresented and are often hyper sexualized when depicted. Sexual objectification of female characters is serious in that female character's body images are distorted to emphasize the sexuality [6] and female gamers' self-efficacy was negatively affected by game play with the sexualized female character and playing a sexualized video game heroine unfavorably influenced people's beliefs about women in the real world [7]. More seriously, gameplaying with a sexualized woman may increase adolescents' acceptance of rape myths that refers to the degree to which someone endorses false, but widely and persistently held, beliefs about rape that approve male sexual aggression against women and tolerance for sexual harassment [8].

If such sexual objectification is something that gamers can explicitly sense by playing the game, there is another serious implicit message in female character's underrepresentation in games. In a contents analysis of four popular massively multiplayer online role-playing games (MMORPG), Waddel et al. [4] found that female characters are seriously underrepresented in quantity and appearance such that female 
characters share only $13.6 \%$ of game characters and $8.4 \%$ of appearances in the game while male characters account for $62.6 \%$ and $57.4 \%$ respectively and such representational portion of female characters are even much less than those of genderless characters. Similar phenomenon is found in even more recent game of Pokemon Go [9] in that female characters have much less appearance and character statistics that represents the ability of the character. Similar underrepresentation of female characters in quantity and ability are found among fighting action games participated in a game show [10]. And such bias against female characters are even worse than TV drama and films where many feminists have argued about $[11,12]$.

This tendency creates even unfavorable stereotyping females in video games in that female characters are sexually provocative and there seldom is strong, independent female protagonist in video games [13]. For lacking strong, independent heroin in the game, Lara Croft in the Tomb Raider is regarded as the role model but still her sexuality has been emphasized even if she is capable and strong in the game [14]. Such sexualization of a female character related to her capability is also found in [3]. Lara Croft series enjoyed commercial success but later that sexy but strong female character is argued as changed to represent dependable feminine image in relation to another strong man, along with the excess of femininity in her appearance by Song [15]. Song criticizes the 'death scene' of Lara Croft in that the death of a male protagonist is usually the death of a hero with tragic feeling but the death of Lara Croft only emphasizes a gore character, where the player stares at her as a third party.

In summary, there exists serious underrepresentation of female characters in quantity (appearance and proportions) and in quality (role importance and ability) other than sexual objectification in video games. Such unfavorable gender distortions against female characters are probably partly due to lack of female developers and experts in the market as stated in [13]. However, Murphy insists that two social science theories contribute to form the stereotype of female characters in general media [12]. The social cognitive theory suggests that people develop expectations for real-world situations from observational learning while consuming media [16]. Also, cultivation theory reveals that representations in the media affect audience's perceptions of reality, but more passively. The theory proposes that continuous exposure to specific cultural messages will influence how the audience identifies with that message in the long-term [17].

In this paper, we are interested in investigating the qualitative underrepresentation of female characters in world famous game, League of Legends (LoL). Developed and published by Riot games in 2009, this game has multi-million players all over the world and has stayed on top ranking of PC room market share in Korea since 2010. In this game, there are two teams consist of 5 players each with different positions: top, middle, bottom, jungle, and support. The goal is to destroy the opposing team's "nexus", a central structure protected by other defensive structures. With such rich pool of players (although there are excessive male players) and API accessible statistics are officially given, LoL has been the theme of many interesting researches. For technical issues, decision tree algorithm is applied to figure out what features are most influential for players to choose their play character (champion) [18] and how gendered and genderless characters are graphically modeled from the ontological view [19]. Also, there exist several player's gender related issues such as how player choose playable character's gender with gender swapping phenomenon [20, 21] and female gamer issues in the players' community [22, 23].

Our interest of the game is, however, the qualitative underrepresentation issue of female characters, not female players. LoL has more than 100 characters called champions that are continuously added every year. Firstly, we want to explore how male and female champions differ in ability as others reviewed [21, 24] but with more statistical parameters and will investigate not only the entry level but the final achievement level so that we can view the designer's intention on the champion's ability with respect to gender.

RQ 1: At the time of 2019, still female champions are in general inferior to male champions? Will that ability difference maintain after players achieve the final level 18 ?

There are six champions categories with respect to their main roles: "Assassin" (champions with high attack ability and burst damage but fragile), "Fighter" (champions with short-ranged combatants with high damage dealt ability), "Mage" (champions with long-ranged combatants, burst damage and crowd control), "Support" (champions with support ability), "Tank" (champions with high defense or damage dealt ability), and "Marksman" (champions with long-ranged combatants and high physical damage ability) [25]. In support champion group, there are two different subgroups called utility support or enchanters and tanker support or catchers. Interestingly, all utility supports are females and tanker supports are mostly males. Thus, we feel that there exists a clear gender-discriminating intention of the LoL designers. We conduct a survey on LoL players who have played supports and ask them how they feel about this gender disproportion of utility supports.

RQ 2: For support champion users, how they feel this gender disproportion of support roles and what makes them to choose their own champion? 


\section{METHOD}

Riot games opened the ability ratings of each champion in defense, attack, magic, and difficulty on LoL's official website [25]. Such information helps players to choose their favorite champions and this is regarded as a good strategy of LoL to keep the character balancing dynamically [26]. Previous studies [21, 24] only analyze these statistics to see if there exists any gender difference from the start of the game and they found that female champions are only in favor of magic power and male champions are better in other categories of ability statistics. In this paper, we do the same analysis but conduct additional analysis on other ability parameter statistics such as attack speed, resistance against magic, regeneration of stamina and magic, moving speed, and effective shooting range by investigating all champions in level 1 and level 18 (the maximum) setting which previous studies did not perform. By doing this, we can see the gender difference of champions from the start and the maximum more clearly. These statistics are for the RQ 1. Since Riot games periodically add champions, current research and previous studies have different champion characters distributions. For example, there were 118 champions in 2014 [24] and 134 champions in 2017 [21]. Our champion distribution statistics is as shown in Table 1 that was accessed May 27, 2019.

Table 1. Distribution of champions with respect to roles and gender

\begin{tabular}{lccccccc}
\hline \multicolumn{1}{c}{ Role } & Male & Rate & Female & Rate & SubTotal & Rate & Female Rate \\
\hline Tanker & 16 & $17.2 \%$ & 3 & $5.9 \%$ & 19 & $13.2 \%$ & $15.8 \%$ \\
Supporter & 9 & $9.7 \%$ & 6 & $11.8 \%$ & 15 & $10.4 \%$ & $40.0 \%$ \\
Marksman & 10 & $10.8 \%$ & 12 & $23.5 \%$ & 22 & $15.3 \%$ & $54.5 \%$ \\
Mage & 18 & $19.4 \%$ & 15 & $29.4 \%$ & 33 & $22.9 \%$ & $45.5 \%$ \\
Fighter & 30 & $32.3 \%$ & 10 & $19.6 \%$ & 40 & $27.8 \%$ & $25.0 \%$ \\
Assassin & 10 & $10.8 \%$ & 5 & $9.8 \%$ & 15 & $10.4 \%$ & $33.3 \%$ \\
Total & 93 & $100 \%$ & 51 & $100 \%$ & 144 & $100.0 \%$ & $35.4 \%$ \\
\hline
\end{tabular}

For RQ 2, we design an online survey with questions.

Q1 : When you use support line, what do you use utility support?

Q2 : Please state the reason why you use or do not use utility support champions.

Q3 : All utility support champions are females. What do you think the reason might be?

We conduct the survey in June 2019 at https://www.op.gg/ where many LoL players exchange their opinions and information. The demographic distribution of our survey subjects is as shown in Table 2.

Table 2. Demographic information of subjects with respect to age group and gender

\begin{tabular}{lcccc}
\hline \multicolumn{1}{c}{ Age } & Male & Female & Total & Rate \\
\hline Teens & 735 & 41 & 776 & $55.10 \%$ \\
$20-24$ & 428 & 37 & 465 & $33.00 \%$ \\
$25-29$ & 119 & 9 & 128 & $9.10 \%$ \\
$>30$ & 28 & 6 & 34 & $2.40 \%$ \\
Unknown & 3 & 2 & 5 & $0.40 \%$ \\
Total & 1313 & 95 & 1408 & $100 \%$ \\
\hline
\end{tabular}

\section{RESULT AND ANALYSIS}

The result of our investigation on champion statistics with respect to gender is summarized in Table 3. Numbers in ability statistics are under the same scale used in [24]. However, two previous studies obtained almost same result by analyzing the officially opened 4 major performance parameter statistics at starting level in that female champions are only better in magic power. Han argued that such result showed the gender stereotype of female characters in that females are worse than males in physical and rational ability but only surreal witcher-like ability was emphasized [24]. In this study, we add other performance parameters and also investigate the maximum level to see if that conjecture still stands while the game is in progress.

With Scheffe's t-test between groups, only female/male category with bold are statistically significant $(\mathrm{p}<0.05)$. At start level, female champions are still inferior to stamina (especially regeneration power) and defence but better in magic as found in 2014 [24] and 2017 [21]. But the attack power seems to be matched as equal although female champions are designed to be better at long range shooting in 2019. When player reaches the maximum level 18, still most statistics are the same as level 1 at the gender difference point of view except increased magic regeneration (emphasize magic power) and overall defence power for female champions. Thus, we can conclude that the gender prototype still stands but a small change is in the process. For RQ2, the first question was if a player would like to play or not to play utility support champions and why. The result is summarized in quantity as shown in Table 4. Recall that all utility support at the time of survey were all females. 
Table 3. Champion performance parameter statistics at level 1 and level 18

\begin{tabular}{lcccccc}
\hline \multicolumn{1}{c}{ Average } & Male Lev 1 & Female Lev. 1 & Female/Male & Male Lev 18 & Female Lev. 18 & Female/Male \\
\hline Attack & 59.92 & 57.49 & 0.96 & 116.81 & 110.21 & 0.94 \\
Attack Speed & 0.64 & 0.64 & 1.00 & 0.90 & 0.88 & 0.98 \\
Stamina & 564.70 & 542.01 & 0.96 & 2091.09 & 2029.34 & 0.97 \\
Stamina Regeneration & 6.83 & 6.12 & $\mathbf{0 . 9 0}$ & 18.56 & 16.68 & $\mathbf{0 . 9 0}$ \\
Magic & 299.45 & 324.58 & $\mathbf{1 . 0 8}$ & 843.54 & 902.25 & $\mathbf{1 . 0 7}$ \\
Magic Regeneration & 8.43 & 8.39 & 1.00 & 17.52 & 18.80 & $\mathbf{1 . 0 7}$ \\
Defence & 31.04 & 28.30 & $\mathbf{0 . 9 1}$ & 90.03 & 87.98 & 0.98 \\
Magic Resistance & 31.44 & 30.55 & 0.97 & 48.08 & 42.74 & $\mathbf{0 . 8 9}$ \\
Moving Speed & 338.33 & 333.10 & 0.98 & 338.33 & 333.10 & 0.98 \\
Shooting Range & 269.41 & 416.67 & $\mathbf{1 . 5 5}$ & 269.41 & 419.00 & $\mathbf{1 . 5 6}$ \\
\hline
\end{tabular}

While the positive rate of using utility support has no effect on gender in Table 4, there actually exist different reasons why they use/not use utility support as shown in Table 5. Female players would not use the utility support champion mainly because of being labeled as Hyeji that means 'easy-going female player gaining points by riding on male player's skill' which was originated from an actual incident happened in 2017 among LoL users. Other than that, most players regardless of gender pointed that the overall ability statistics were lower than other roles. The Hyeji incident and similar so called 'queen bee female players' riding on skilled male friend's performance creates negative gender prototype on female gamers [27] and even provokes mysogyny among young Korean gamers [28].

Table 4. Players' responses on the use of utility support

\begin{tabular}{ccccc}
\hline Utility Support & Male & Female & Total & Positive Rate \\
\hline Yes & 878 & 64 & 942 & $69.0 \%$ \\
No & 392 & 31 & 423 & $31.0 \%$ \\
Total & 1270 & 95 & 1365 & \\
Positive Rate & $69.1 \%$ & $67.4 \%$ & & \\
\hline
\end{tabular}

Table 5. Players' responses why they use of utility

\begin{tabular}{cc} 
& support \\
\hline Rank & Reason \\
\hline 1 & Accessible (Cheap and Easy to control) \\
2 & Beautiful Skin \\
3 & Healing and defending are my trait \\
4 & Not Exhaustive \\
\hline
\end{tabular}

However, once they decided to use utility support, the best reason is the accessibility and beautiful skin/appearance. Thus, we can also imagine that the female champions' sexuality takes a role here. However, although we have only $7 \%$ of female players in this survey, females do not excessively choose utility lines which were found differently in [21]. On Q3 of the survey which asks "What do you think the reason of all utility supports are females?", the top 3 frequent opinions are 'Heal is for female, combat is for male', 'Healing reminds me of mother or sister', and 'How come players can feel natural when tumultuous male gives healing and small beautiful girl sacrifices for the team as a tanker? The opposite is what we have learned so far and it is common in the society". Many subjects also point out that it might be Riot Game's intentional use of gender prototype for marketing reason and they feel that it is not politically correct but accept that intention because the majority players of the game are males. Such opinions are common to all subjects but the group of female users who responded they did not play utility support. The majority of that group's opinion is that the utility support is easy to control thus entry level female users would take that but they don't since they are already experienced users.

Due to various expressions subjects made and more than thousand answers were collected, it is hard to taxonomize their answers in quantity but we can clearly see the existence of common gender prototyping and the influence of social role theory [29]. Similar phenomenon is found in other combat game like Overwatch in that players have gender prototype against female gamer in that she must take healer role because she is female regardless of play skill [30]. Another group of LoL players responded in this survey point out that such 'all-female-champions' for utility support setting is due to technical reasons. LoL enjoys now many seasons of success and there are many high level rankers' available and female LoL gamers are increasing only very recently. Thus it is natural for entry level female players choose utility support thus Riot games intentionally use beautiful skins to decorate female utility supports to induce new entry level female players. There is no significant age effect on answers of Q3.

\section{CONCLUSION}

As female gamers are rapidly increasing all over the world, video game is no longer "white male's territory". In Korea, recent report by government agency reveals that female gamers enjoy as many hours of game play as males especially in mobile platform and age group under 30 . In combat oriented genre such as 
first person shooter (FPS) and multi-player online battle arena (MOBA), still male gamers are in majority but there is noticeable increase of female gamers for the likes of overwatch and unknown's battleground.

However, underrepresentation of female characters in video games is still underway in quantity and in quality. In this paper, we investigate world leading MOBA game LoL for that theme. Firstly we analyze how the average ability statistics and subsequent performance related parameters are designed differently at the entry level (level 1) and the most experience level (level 18). The result show that still female champions are only superior to male champions in 'unreal' magic power and inferior to male champions in many ways especially at the starting level which was already argued since 2014. There is, however, only a slow increase in defensive power for female champions at the maximum level compared with 2014 statistics. Such gender difference in champion's given statistics together with small proportion of female champions (less than 40\% of all selectable champions), female players are naturally disadvantageous in performance if they choose female champions in play as previous studies already found.

We also report that there exists a serious gender disproportion among support role champions. In support role champions, there are two subgroups called utility and tank where utility support usually takes a healer role and tank support takes sacrificing role to neuter opponent's attack. All utility supports are females and most tank supports are males.

We take a survey of 1,403 LoL players (93\% are males) who have played utility or tank support and asks why they prefer/unprefer 'all-female' utility support champion and how they feel such gender disproportion. Interestingly, female players who do not play utility support champions avoid such champions due to negative labeling of 'easy riding female gamer' where males give no such responses at the same question. Most players of both genders use utility support because they are cheap and easy to control and usually have beautiful appearances (skins). Also, most subjects in our survey explain that such "all-female" utility support is naturally accepted although they feel it may not be politically correct to have such gender stereotype learnt by the society-healing is female's role and combat is male's role.

Either that was intentional or just for marketing decision, LoL is not free from such gender prototyping and negative social role theory based gender disproportion of champions. With continuously increasing female gamers, game designers should be more sensitive to create game characters even though that game was male excessive combat-oriented games and unfortunately, LoL is changing forward but way too slow in this aspect.

\section{REFERENCES}

[1] Bessenoff G. R., "Can the media affect us? Social comparison, self-discrepancy, and the thin ideal," Psychology of Women Quarterly, vol. 30, pp. 239-251, 2016.

[2] Miller M. K. and Summers A., "Gender differences in video game characters' roles, appearances, and attire as portrayed in video game magazines," Sex roles, vol. 57, no. 9-10, pp. 733-742, 2007.

[3] Lynch T., Tompkins J. E., van Driel I. -I., Fritz N., "Sexy, strong, and secondary: A content analysis of female characters in video games across 31 years," Journal of Communication, vol. 66, no. 4, pp. 564-584, 2016.

[4] Waddell T. F., et al., "White man's virtual world: A systematic content analysis of gender and race in massively multiplayer online games," Journal for Virtual Worlds Research, vol. 7, no. 2, pp. 1-14, 2014

[5] Downs E., Smith S. L., "Keeping abreast of hypersexuality: A video game character content analysis," Sex roles, vol. 62, no. 11-12, pp. 721-733, 2010.

[6] Martins N., Williams D. C., Harrison K., Ratan R. A. "A content analysis of female body imagery in video games," Sex roles, vol. 61, no. 11-12, pp. 824-836, 2009.

[7] Behm-Morawitz E. and Mastro D., "The effects of the sexualization of female video game characters on gender stereotyping and female self-concept," Sex roles, vol. 61, no. 11-12, pp. 808-823, 2009.

[8] Driesmans K., Vandenbosch L., Eggermont S., "Playing a videogame with a sexualized female character increases adolescents' rape myth acceptance and tolerance toward sexual harassment," Games for health journal, vol. 4, no. 2, pp. 91-94, 2015.

[9] Han S. H., "Glass ceiling in video games-Unequal gender status in Pokmon Series," Journal of Korea Game Society, vol. 17, no. 6, pp. 173-188, 2017.

[10] Han S. H., "Analyzing the Status of Female Characters in Fighting Action Games: Focus on EVO 2016," Journal of Korea Game Society, vol. 16, no. 5, pp. 79-88, 2016.

[11] Kwon D. -K., "A study on the shapes and distinct features of female character in Korean games," Journal of Institute for Humanities and Social Sciences, vol. 12, no. 2, pp. 115-137, 2011.

[12] Murphy, J. N., "The role of women in film: Supporting the men-An analysis of how culture influences the changing discourse on gender representations in film," PhD dissertation, The University of Arkansas, 2015.

[13] Kondrat, X., "Gender and video games: How is female gender generally represented in various genres of video games?," Journal of Comparative Research in Anthropology and Sociology, vol. 6, no. 1, pp. 171-193, 2015.

[14] Jansz J. and Martis R. G., "The Lara Phenomenon: Powerful Female Characters in Video Games," Sex Roles, vol. 56, no. 3-4, pp. 141-148, 2007.

[15] Song S., "A Study on Gender Identity of Female Hero Characters in Video Games," M.A. Thesis, Ewha Women's University, 2016. 
[16] Hall P., West J., McIntyre E., "Female self-sexualization in MySpace.com personal profile photographs," Sexuality \& Culture, vol. 16, no. 1, pp. 1-16, 2012.

[17] Eyal K., Raz Y., Levi M., "Messages about sex on Israeli television: Comparing local and foreign programming," Journal of Broadcasting \& Electronic Media, vol. 58, no. 1, pp. 42-58, 2014.

[18] Zhang X., Yue Y., Gu X., Niu B., Feng Y. Y., "Investigating the Impact of Champion Features and Player Information on Champion Usage in League of Legends," Proceedings of the 2017 International Conference on Information Technology, 2017, pp. 91-95.

[19] Han H. W. and Koo H. -I., "Analysis of Ontological Representation of AOS Game Character-focused on <League of Legends>," Journal of Korea Game Society, vol. 15, no. 1, pp. 185-198, 2015.

[20] Ratan R. A., Fordham J. A., Leith A. P., Williams D., "Women keep it real: Avatar gender choice in League of Legends," Cyberpsychology, Behavior, and Social Networking, vol. 22, no. 4, pp. 254-257, 2019.

[21] Gao G., Min A., Shih P. C., "Gendered design bias: Gender differences of in-game character choice and playing style in League of Legends," Proceedings of the 29th Australian Conference on Computer-Human Interaction, pp. 307-317, 2017.

[22] Kim S. J., "Gender inequality in eSports participation: examining League of Legends," Doctoral dissertation, University of Texas at Austin, 2017.

[23] Canossa A., Witkowski E., Ozkaynak D., "Over-lenient and over-aggressive behaviors: Gender play in League of Legends," Behavior Analytics, 2015

[24] Han H. -W., Kim S. -Y., Koo H. -I., "Analysis of Gender Identity of On-line Game Character-focused on <League of Legends>," Journal of Korea Game Society, vol. 14, no. 5, pp. 147-160, 2014.

[25] "League of Legends," 2019. [Online]. Available: http://na.leagueoflegends.com/.

[26] Han S. -W., Lee J. -J., Park J. -W., "The Case Study on Game Balancing for Player VS Player Fighting Game," Journal of Korea Game Society, vol. 14, no. 1, pp. 13-25, 2014.

[27] Song D. H., Park S., Yang S. W., Yang Y., Won K., "Gender Differences and Gender Stereotype in Play Style among Young Korean Gamers," The Journal of the Korea Institute of Information and Communication Engineering, vol. 21, no. 1, pp. 72-81, 2017.

[28] Song D. H., "Analysis of Korean Gamers' Personality Patterns with respect to the Victim/Attacker of the Misogyny and the Misandry in Game Playing," Journal of the Korea Institute of Information and Communication Engineering, vol. 22, no. 11, pp. 1481-1488, 2018.

[29] Koenig A. M. and Eagly A. H., "Evidence for the social role theory of stereotype content: Observations of groups' roles shape stereotypes," Journal of Personality and Social Psychology, vol. 107, no. 3, pp. 371-392, 2014.

[30] Song D. H., Rhee H. K., Kim J. H., "Gender stereotype and hostile sexism among young Korean gamers based on teammate selection strategy and game style preferences," Indonesian Journal of Electrical Engineering and Computer Science (IJEECS), vol. 19, no. 3, pp. 1512-1518, 2020.

\section{BIOGRAPHIES OF AUTHORS}
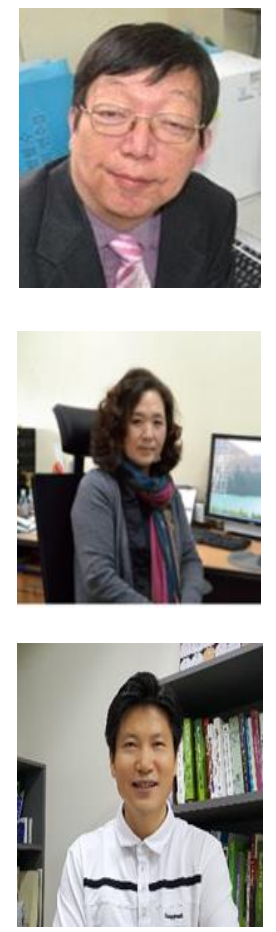

Doo Heon Song received his B.S. from Seoul National University, Korea in 1981 and M.S. from the Korea Advanced Institute of Science and Technology in 1983 in Computer Science. He received his Ph.D. Certificate in Computer Science from the University of California at Irvine, USA in 1994. He has been a professor at Department of Computer Games, Yong-in SongDam College, Korea, since 1997. His research interests include machine learning, artificial intelligence, fuzzy systems, medical image processing, and computer game design. He is currently the associate editor of Journal of Information and Communication Convergence Engineering

Hae Kyung Rhee obtained her B.S. from Sungsil University, Korea in 1979, M.S. from University of Illinois at Urbana-Champaign, USA in 1985, Ph. D. at Sungkunkuan University, Korea in Computer Science in respectively. She has been a professor at Department of Computer Games, Yong-in SongDam College, Korea, since 2001. Her research area includes database development, data modeling in Game design, Information Security.

Jeong Hoon Kim received his B.S. from Seoul University, Korea in 1991 and M. S. from Yonsei University, Korea in 1994 in Computer Science. He was one of key developers of online MMORPG Lineage tournament from NCSoft during 1999-2001 and developed several mobile games in Softgen. Inc. until 2003. He joined with faculty members of Department of Computer Games, Yong-in SongDam College, Korea since 2003. His research interests include developing mobile games and online games. 